\title{
Correction to: Fracture of Sn-3.5\%Ag Solder Alloy Under Creep
}

\author{
V.I. IGOSHEV, ${ }^{1}$ J.I. KLEIMAN,${ }^{1}$ D. SHANGGUAN,${ }^{2}$ S. WONG, ${ }^{3}$ \\ and U. MICHON ${ }^{4}$ \\ 1.-Integrity Testing Laboratory Inc., 80 Esna Park Drive, Units 7-9, Markham, ON L3R 2R7, \\ Canada. 2.-Visteon Automotive Systems, Deaborn, MI 48121, USA. 3.-Visteon Automotive \\ Systems, Markham, ON, Canada. 4.-ESPEO.3, Universite D’Orleans, Orléans, France.
}

\section{Correction to:}

\section{Journal of ELECTRONIC MATERIALS,}

Vol. 29, No. 12, 2000

https://doi.org/10.1007/s11664-000-0119-z

In the original article, there is an error in Fig. 8. Following is the corrected figure.

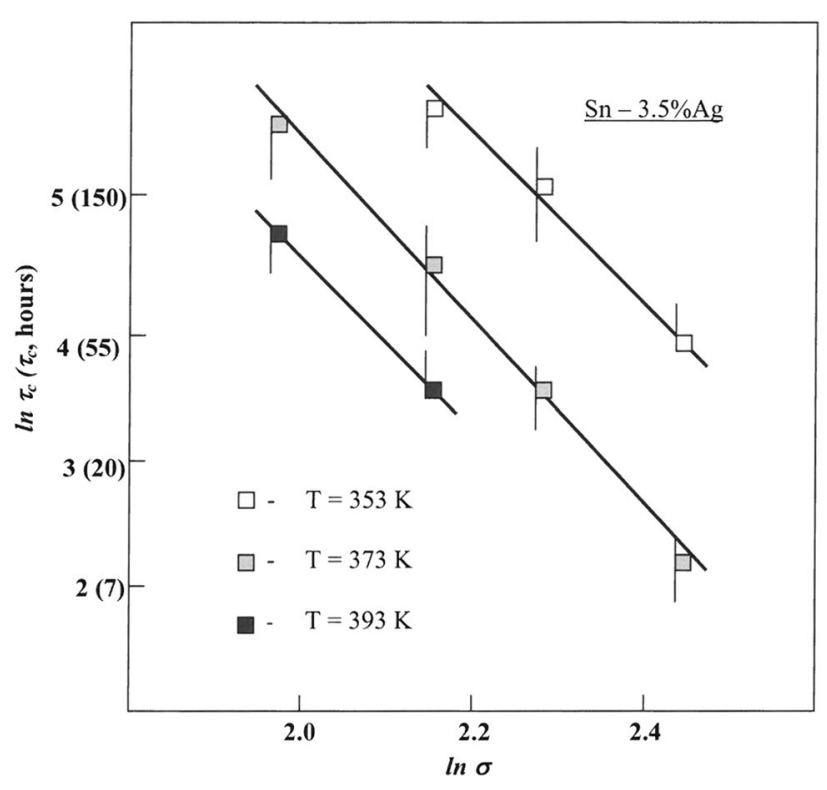

Fig. 8. Dependence of specimen (Sn-3.5\%Ag solder alloy) lifetime $\tau_{\mathrm{c}}$, vs. the applied creep stress $\sigma$ at different temperatures. 